\title{
Menumbuhkan Semangat Pengusaha Muda Siswa SMA 6 Tangerang Selatan
}

\author{
Mulyadi $^{{ }^{*}}$, Yanurianto ${ }^{2}$, Hastono $^{3}$, Dian Rostikawati $^{4}$, \\ Kharisma Danang Yuangga ${ }^{5}$ \\ 1,2,3,4,5 Program Studi Manajemen, Fakultas Ekonomi, Universitas Pamulang \\ Jl. Surya Kencana No.1, Pamulang Barat, Kec. Pamulang \\ Kota Tangerang Selatan, Banten 15417 \\ *Penulis Korespodensi: dosen00031@unpam.ac.id
}

\begin{abstract}
ABSTRAK
Tujuan kegiatan ini adalah menumbuhkan semangat pengusaha muda ini sangat dibutuhkan sesuai dengan kebutuhan para siswa saat ini. Oleh sebab itulah pada PKM ini akan diberikan penyuluhan menumbuhkan semangat pengusaha muda siswa SMA 6 Tangerang Selatan. Dalam kegiatan ini metode yang diterapkan diharapkan dapat memberikan kemudahan kepada para mahasiswa SMA 6 Tangerang Selatan. Metode yang digunakan adalah metode diskusi kelompok, sharing, tanyajawab, praktik yang di damping oleh pemateri. Pada metode penjelasan, setiap instruktur menyampaikan materi terkait dan membuat tampilan visual berupa slide power point yang ditampilkan ke layar dengan LCD proyektor. Hasil kegiatan memberikan pemahaman baru kepada siswa dalam melakukan pengelolaan binis tidak harus selalu dengan nominal uang yang besar, atau mekanisme yang rumit. Mereka dapat melakukannya secara berkelompok, atau sendiri dari rumah. Siswa dapat mendapatkan ilmu pengetahuan baru, sehingga bisa dimaksimalkan potensi diri dengan kreatif dan inovatif.

Kata Kunci :Wirausaha
\end{abstract}

\begin{abstract}
The purpose of this activity is to foster the spirit of young entrepreneurs is needed in accordance with the needs of students today. That is why the PKM will be given counseling to foster the enthusiasm of young entrepreneurs of SMA 6 Tangerang Selatan students. In this activity the method applied is expected to provide convenience to students of South Tangerang 6 High Schools. The method used is the method of group discussion, sharing, question and answer, practice accompanied by the speaker. In the explanation method, each instructor conveys related material and makes a visual display in the form of a power point slide that is displayed on the screen with the projector's LCD. The results of activities provide new understanding to students in managing business not necessarily with large amounts of money, or complicated mechanisms. They can do it in groups, or alone from home. Students can get new knowledge, so they can maximize their potential with creativity and innovation.
\end{abstract}

Keywords: Entrepreneurship 


\section{PENDAHULUAN}

Beberapa Siswa SMA 6 Tangerang Selatan memiliki minat berwirausaha yang tinggi. Hal itu ditunjukkan dengan kegiatan wirausaha yang dilakukan siswa di lingkungan sekolah. Menjadi reseller, drop shiper atau bahkan endorser, baik untuk produk orang lain ataupun produk buatan sendiri . Fenomena tersebut menimbulkan budaya berwirausaha di lingkungan sekolah menggeliat. Sayangnya mayoritas siswa berwirausaha dengan kemampuan skill yang terbatas (Munfaqiroh, 2018), sehingga baik pengalaman maupun profit yang didapatkan oleh mereka kebanyakan masih belum maksimal. Beberpa diantaranya masih kurangnya pemahaman dan pengetahuan para remaja khususnya siswa dalam Semangat pengusaha muda mandiri, siswa yang memiliki kegiatan usaha dalam hal mengatur diri dan membuat perencanaan binis yang baik. Hal itu dikarenakan para siswa mayoritas masih belum memiliki pemahaman dan sikap dalam Semangat pengusaha muda yang baik (Sumarsono, 2016).

SMA 6 Tangerang Selatan memiliki nama baik yang cukup bagus di mata masyarakat. Salah satu sekolah unggulan yang ada di Tangerang Selatan, SMA 6 Tangerang Selatan selalu berupaya mencetak lulusan yang tidak hanya cakap dalam bidang akademis dan non akademis, tetapi juga memiliki karakter yang siap bersaing dalam secara intelektual.

Sebagai salah satu SMA Unggulan di Tangerang Selatan, SMA 6 Tangerang Selatan berkewajiban membentuk mindset dan ketrampilan peserta didiknya agar mampu bersaing di era milenial saat ini. Salah satunya adalah dengan mengembangkan skill kewirausahaan para siswa. Agar Siswa dapat memiliki semangat berwirausaha yang terstruktur sejak dini, mampu memetakan diri dan dapat membuat branding diri dan produk yang dibuat

Perlu upaya menumbuhkan kembali jiwa kewirausahaan siswa (Lastariwati, 2013). Upaya itu tentu perlu dukungan dari semua pihak, tidak hanya sekolah. Kewirausahaan merupakan suatu proses untuk mengembangkan atau menerapkan suatu ide inovatif dalam memanfaatkan peluang mendapatkan sesuatu yang bernilai (Suryana, 2014). Sehingga, pengembangan potensi itu sangat baik diterapkan dalam diri sebagai bentuk manajerial dalam kehidupan.

Banyak orang yang keliru menganggap berwirausaha itu hanya berdagang saja. Padahal, berwirausaha itu bisa berupa apa saja (Nur Firdaus, 2014). Perlu mengubah mindset pikiran agar siswa memiliki jiwa berwirausaha sejak dini. Karena sekarang ini, ketika lulus sekolah, anak-anak lebih menyukai sesuatu hal yang serba instan, yaitu lebih memilih bekerja menjadi buruh, dibandingkan membuka usaha atau berwirausaha.

Sekolah adalah untuk mencetak siswa agar memiliki suatu keahlian sebagai bekal menghadapi dunia kerja (Marmoah, 2018). Tapi akan lebih baik, jika siswa berinovasi untuk membuka usaha dan memiliki usaha sendiri (Koranti, 2013). Dengan begitu dapat memberikan kesempatan kerja bagi orang lain. Dengan harapan di masa depan dengan berwirausaha pendapatan akan berbeda. Ketika menjadi pekerja, maka penghasilannya hanya mengsiswalkan gaji dari perusahaan yang diterima setiap bulan dengan nilai gaji yang sama. Sedangkan menjadi pengusaha pendapatannya tak terbatas, bergantung dari diri inovasi sendiri. Kalau ingin berpenghasilan banyak, 
Mulyadi, dkk

usahanya lebih rajin dan waktupun kita yang menentukan. Hal itu sangat berbeda dengan pekerja.

Bagi sebagian orang, berjualan atau berwirausaha bukanlah suatu pekerjaan, melainkan sebuah profesi (Z. Heflin Frinces, 2010). Sedangkan menjadi buruh adalah suatu pekerjaan yang bisa disebut bekerja. Namun, tak jarang orang merasa malu jika dirinya berjualan atau usaha sendiri. Berbeda jika dirinya bekerja sebagai buruh, dengan pakaian rapi. Tetapi waktu diatur perusahaan dan pendapatan terbatas.

Program pengabdian kepada masyarakat merupakan salah satu program yang wajib dilaksanakan, baik oleh dosen maupun oleh mahasiswa, dengan berlsiswaskan pada prinsip-prinsip: motivasi pemenuhan kompetensi akademik, jiwa kewirausahaan (entrepreneurship), dan profesional, sehingga dapat menghasilkan program pengabdian kepada masyarakat yang bermutu, relevan, dan sinergis dalam meningkatkan pemberdayaan masyarakat.

Untuk itulah tim dosen program studi Manajemen mengadakan Pengabdian Kepada Masyarakat untuk menumbuhkan semangat pengusaha muda sebagai bentuk kepedulian kepada Siswa SMA 6 Tangerang Selatan. Pelatihan ini akan melakukan pendekatan kekinian sehingga dapat lebih mudah dipahami oleh siswa SMA 6 Tangerang Selatan yang rata-rata adalah pemuda dan remaja siswa yang up to date dengan keadaan saat ini.

\section{METODE PELAKSANAAN}

Metode pelaksanaan memaparkan tahapan yang perlu dilakukan mulai dari perencanaan / pengusulan hingga pelaporan dalam suatu rangkaian kegiatan pelaksanaan pengabdian kepada masyarakat. Metode pelaksanaan dalam kegiatan pengabdian kepada masyarakat ini diawali dengan melakukan surve lokasi di SMA 6 Tangerang Selatan atas ketertarikan tim pengusul berdasarkan pengamatan sehari-hari, yaitu siswa kurang terliterasi binis karena banyak yang tidak memiliki pengelolaan binis sederhana yang jelas.

\section{HASIL DAN PEMBAHASAN}

Pengelolaan binis sederhana untuk siswa SMA 6 Tangerang Selatan diharapkan mampu memberikan visi dan semangat baru dalam upaya siswa meraih cita-cita. Pengelolaan binis sederhana ini adalah dasar yang akan digunakan oleh siswa untuk membentuk mindset, kemampuan berpikir hemat, cermat dan ekonomis. Sehingga akan berdampak pada perilakunya menggunakan uang baik di sekolah maupun di rumah.

Dengan pengelolaan binis yang mantab, siswa akan lebih bisa fokus dalam belajar, dapat mengatur diri dengan baik, memiliki tujuan yang pasti, serta akan membuatnya mampu berpikir secara rasional. Siswa akan lebih mengenal dirinya sendiri, potensi yang dimiliki serta upaya yang dapat dilakukan untuk meraih keinginannya dan dapat menikmati prosesnya dengan benar.

Group Discusion yang digunakan sebagai model penyampaian materi dirasa sangat efektif, siswa lebih dapat terbuka dalam menyampaikan keresahannya tentang masa depan dengan suasana yang santai dan terbuka. Mencurahkan permasalahn binis yang ternyata tidaklah sederhana yang seperti perkiraan sebelumnya. Seluruh perserta diajak mengutarakan permasalahan untuk kemudian dipecahkan bersama-sama. 
Kebanyakan siswa yang menjadi peserta masih belum memiliki dasar yang kuat dalam pengelolaan binis, sehingga gaya hidup mereka cenderung boros, impulsif dan menjadi siswa yang sangat konsumtif.

Pengisian lembar kerja yang dilakukan individu, lebih banyak menyadarkan siswa tentang apa yang sebenarnya mereka inginkan, siapa mereka, dan apa yang mereka harapkan di masa yang akan datang. Pengisian itu dilakukan secara individu setelah siswa mendapatkan serangkaian materi tentang pengelolaan binis. Siswa diajak untuk membuka dirinya dan jujur mengenai keinginan di masa yang akan datang setelah diberikan waktu untuk membuat pos pengeluaran dengan cermat.

Pengelolaan binis sederhana di SMK mendapatkan hasil yang sangat baik. Siswa lebih peka terhadap diri dan ke mulai dapat mengambil sikap untuk menentukan apasaja yang harus diraih dan ditempuh untuk mewujudkan rencana binisnya tersebut, meski belum terkondidikan dengan baik, mereka mampu memberikan pemaparan akan perncanaan binisnya di masa yang akan datang. Kegiatan ini juga menjadi inspirasi bagi siswa yang belum memulai kegiatan usaha, namun sudah memiliki semangat usaha dalam dirinya.

\section{PENUTUP}

Hasil kegiatan PKM di SMA 6 Tangerang Selatan berjalan dengan lancar. Siswa terlihat antusias mempelajari materi dalam kegiatan PKM Menumbuhkan Semangat Pengusaha Muda Siswa SMA 6 Tangerang Selatan, Selain itu kiat-kiat sukses dan membangun diri menjadi pribadi yang kratif dan inovatif juga memberikan pemahaman baru kepada siswa dalam melakukan pengelolaan binis tidak harus selalu dengan nominal uang yang besar, atau mekanisme yang rumit. Mereka dapat melakukannya secara berkelompok, atau sendiri dari rumah. Siswa dapat mendapatkan ilmu pengetahuan baru, sehingga bisa dimaksimalkan potensi diri dengan kreatif dan inovatif.

\section{DAFTAR PUSTAKA}

Koranti, K. (2013). Analisis Pengaruh Faktor Eksternal dan Internal terhadap Minat Berwirausaha. Proceeding PESAT (Psikologi, Ekonomi, Sastra, Arsitektur \& Teknik Sipil) Bandung, 8-9 Oktober 2013.

Lastariwati, B. (2013). Pentingnya kelas kewirausahaan pada SMK Pariwisata. Jurnal Pendidikan Vokasi. https://doi.org/10.21831/jpv.v2i1.1018

Marmoah, S. (2018). Administrasi dan Supervisi Pendidikan Teori dan Praktek. Deepublish.

Munfaqiroh, S. (2018). FAKTOR YANG MEMPENGARUHI WIRAUSAHA WANITA MISKIN UNTUK MENCAPAI KEBERHASILAN USAHA. Jurnal Ilmiah Bisnis Dan Ekonomi Asia. https://doi.org/10.32812/jibeka.v10i2.74

Nur Firdaus. (2014). Pengentasan Kemiskinan melalui Pendekatan Kewirausahaan Sosial Poverty Alleviation Through Social Enterpreneurship. Jurnal Ekonomi Dan Pembangunan. https://doi.org/10.1108/02630801011070966 
Mulyadi, dkk

Sumarsono, H. (2016). FAKTOR-FAKTOR YANG MEMPENGARUHI INTENSI WIRAUSAHA MAHASISWA UNIVERSITAS MUHAMMADIYAH PONOROGO. Ekuilibrium : Jurnal Ilmiah Bidang Ilmu Ekonomi. https://doi.org/10.24269/ekuilibrium.v8i1.35

Suryana. (2014). Pengertian Kewirausahaan. Hilos Tensados. https://doi.org/10.1017/CBO9781107415324.004

Z. Heflin Frinces. (2010). Pentingnya Profesi Wirausaha Di Indonesia. Jurnal Ekonomi Dan Pendidikan. 